\title{
Great Apes and Human Development: A Personal History
}

\author{
Michael Tomasello ${ }^{1,2}$ \\ ${ }^{1}$ Duke University and ${ }^{2}$ Max Planck Institute for Evolutionary Anthropology
}

ABSTRACT_In this article, I recount my history of research with great apes. From the beginning, the idea was to compare apes to human children, with an eye to discovering facts relevant to describing and explaining processes of human development. The research went through three more or less distinct stages, focusing on communication and social learning, social cognition and theory of mind, and cooperation and shared intentionality. I conclude by identifying problems and prospects for comparative research in developmental psychology.

KEYWORDS—evolution; development; apes

I wish I could say it was all planned. But the fact is, I lucked into the opportunity to study great apes. Although from my first psychology course as an undergraduate at Duke University I thought about things evolutionarily, my graduate work at the University of Georgia was almost totally developmental. True, the focus was on Piaget, a biologist with an evolutionary perspective, but the research was all about children.

It was pure luck that I happened to get a job (barely) at Emory University, home of the Yerkes Primate Center. Soon after arriving in 1980, I drove out to the Yerkes Field Station with a colleague. We were gushing enthusiastically about how incredibly similar chimpanzees were to humans - in their basic emotions, their playful social interactions, their clever use of tools - when one of them sitting atop a climbing apparatus began urinating. Another sauntered over and opened its mouth

Michael Tomasello, Duke University and Max Planck Institute for Evolutionary Anthropology.

Correspondence concerning this article should be addressed to Michael Tomasello, Department of Psychology and Neuroscience, Duke University, Box 90086, Durham, NC 27708-0086; e-mail: michael.tomasello@duke.edu.

C) 2018 The Author

Child Development Perspectives $\odot 2018$ The Society for Research in Child Development DOI: $10.1111 /$ cdep.12281 to catch the pee. Well, okay, maybe very similar to us, but not identical! At more or less that moment, I could dimly see how exciting it would be to directly compare great apes and human children on the kinds of phenomena that I and other developmental psychologists were studying.

\section{COMMUNICATION AND SOCIAL LEARNING}

At the time, I was studying language acquisition. Prominent researchers such as Bruner (1) and Bates (2) were emphasizing the pragmatics of the process, including the role of joint attention in word learning and the status of the pointing gesture as the most basic act of reference. So one thing that caught my eye on that first day was the way the young chimpanzees gestured to one another, especially during play. What was remarkable was that these gestures did not seem to be the kind of fixed action patterns characteristic of the phylogenetically ritualized communicative signals studied by ethologists. They seemed to be more under the intentional control of the individual for flexible use as needed in particular circumstances. What they looked like were human infants asking to be picked up using an arms-up gesture toward an adult. That is, they seemed similar to the intention movements studied by ethologists, except that individuals actually learned them from their social interactions and also had intentional control over them.

Over a series of observational studies published in animal behavior journals, we established that chimpanzees had a number of gestures that were learned individually and used intentionally (see 3 for a review). They used these gestures flexibly (same gesture for different ends, same end effected by different gestures), even waiting for a response from the recipient, and repeated the gesture if the desired response was not forthcoming. And their use of the gestures was tailored to the recipients' attentional state: When their intended recipient was not looking, their gestures were never visual but mostly auditory or tactile. Although these gestures were of the same type as human infants' ritualizations, such as the arms-up gesture, they clearly differed from human infants' pointing and iconic gestures. Pointing and 
iconic gestures are referential, aimed at establishing joint attention, and it did not seem that the ape gestures were doing, or even aimed at doing, that. As joint attention was the main topic of my research on language acquisition at that time, I felt we were zeroing in on both the similarities and the differences between gestural communication in apes and infants (4).

But Goodall (5) made another claim about ape gestures that did not ring true to me. She maintained that each group of chimpanzees had a different repertoire of gestures that they passed along to one another culturally, by imitation, like human languages. So one of the questions we investigated, both observationally and experimentally, was whether apes were indeed imitating one another (as opposed to ritualizing the gestures in interaction), and we concluded that they were not. The cultural claim was also being made about chimpanzees' use of tools, and this seemed, on the surface, to be more plausible. But tool use is complicated. One could simply emulate the outcome (using a tool to open a box, like a demonstrator, but using it in one's own way), or one could actually copy the body movements or possibly the cognitive strategies of the demonstrator. This led to a series of studies on great apes' social learning of tool use. The novelty here was that in this case we also needed to test children because it was not clear exactly which aspects of tool use they would reproduce if we broke it down in that fine-grained way. In this way, our comparative experiments were born (for the first, see 6). Our conclusion, based on several studies, was that chimpanzees emulated and human children imitated.

Subsequent research by Whiten (7) and my team (8) has required softening that claim somewhat. But it still mostly holds, and we (9) argued that this difference in social learning accounted for the fact that chimpanzee culture was tentative and fragile, whereas human culture was so well entrenched that its products and practices could ratchet up in complexity over time cumulatively. And I (10-12) argued that this process of cumulative cultural evolution accounts for human groups having such complex technologies, symbol systems, and institutions.

\section{SOCIAL COGNITION AND THEORY OF MIND}

With a new method in hand, Josep Call and I set out to explore the issues raised by Premack and Woodruff (13) in their seminal article, "Do Chimpanzees Have a Theory of Mind?" In that work, the topic was how chimpanzees understand human intentions. But then, based on discussions by philosophers and research by developmentalists, questions arose about the understanding of other mental states. In some studies, we took experimental protocols from developmental research and applied them to apes, and in others, we made explicit comparisons to children, either in the same study or in an accompanying study. From the beginning, we encountered criticisms that the setting and methods for the children and the apes were not identicalwhich of course they were not-but we persisted (see subsequent sections of this article).
In our early studies, we were mostly getting negative results with the apes, as were Povinelli and colleagues (14). But almost all those studies used experimental paradigms in which the ape's task was to cooperate with an experimenter, typically through some form of communication. For example, when an ignorant or knowledgeable human points to where food is hidden, apes do not get it no matter who is pointing. But then came a breakthrough. Brian Hare had the idea to design an experiment that mimicked Kummer's observation that subordinate baboons in the wild sometimes get away with something even if a dominant baboon is nearby - if he can be certain that the dominant's view is blocked by a rock or some bushes. With Call, we designed a series of such studies and found that, lo and behold, chimpanzees could tell when a dominant competitor either did or did not see food (because a barrier either was or was not present). We later found that they could also tell when a dominant competitor knew the food was behind a barrier-because he had seen it placed there previously (even though he could not see it at the moment). And then we found that chimpanzees would actually move several yards to a place where a dominant was unable to see them behind a barrier so they could take the food (15-17).

Reflecting on those studies, we decided that one of the keys was that chimpanzees were competing with one another, not communicating with a human cooperatively. Based on this insight, we established that chimpanzees do indeed understand others' goals and intentions (even when, as in failed attempts and accidents, that understanding does not match their behavior). Coupled with their understanding of seeing and knowing, this meant that they have a mentalistic theory of how others operate: They understand that others have goals and that they perceive the world to see how and when they can meet those goals. Thus, we claimed that apes have a kind of perception-goal psychology that differs from humans' belief-desire psychology in that they do not understand beliefs as mental representations that might or might not match reality (18). Recently, we changed our conclusion somewhat because we found that apes look in anticipation at where an individual goes based on an understanding that she has a false belief, that is, they do well in implicit tests used with human infants (19; see also 20) - but in many studies, they still do not make behavioral decisions based on others' beliefs.

\section{COOPERATION AND SHARED INTENTIONALITY}

So chimpanzees and other apes understood others' mental states when they competed with them. But how about cooperation? Alicia Melis, Hare, and I designed a study to take advantage of chimpanzees' competitive nature: We put them in teams so they needed to cooperate to compete (21). The apparatus we used, modeled on a study from the1930s, was a box of rocks so heavy that it required two chimps to pull it in (using ropes). We almost broke our backs setting up the experiment every day. But then a 
colloquium speaker, Satoshi Hirata, quite innocently showed us studies he was doing using an apparatus comprising only a single wooden plank with a rope threaded through some hooks so that when one individual pulled, nothing happened, but when individuals pulled together, the mechanism worked. Backs aching, we asked his permission to use this apparatus and we had a paradigm.

Using this paradigm - often comparing the apes to human children for whom there was little previous work on collaboration of this type (the exception being some wonderful studies by Brownell, e.g., 22)—Warneken and I (23) found that apes were skillful in some ways but not in other ways. One limit was that they had trouble dividing the spoils of the collaboration in a way that kept both of them happy. Typically, the dominant ape just took the food and the subordinate soon quit cooperating. Human children had no problem dividing the spoils in mutually satisfactory ways over many trials. Similarly, children would keep collaborating until their partner got a reward, even if, by accident, they got their reward prematurely. Apes worked only until they got their reward and then they were done, their partner be damned. Also, if their partner stopped collaborating, apes either gave up or tried to get the reward on their own, whereas human infants typically beckoned or gestured the partner back into his or her role. Children also excluded noncollaborators (free riders) from the spoils, whereas chimpanzees did not. When a partner did not play his role well, children, but not apes, attempted to get him or her back on track. And there were other findings. The point is that human children, but not great apes, show many signs of creatures who are specifically adapted for collaborating with others.

At some point during all this, I attended a philosophy workshop at the University of Leipzig on shared intentionality. Gilbert presented a version of her famous paper, "On Taking a Walk Together" (24). Her main point was that in a simple exchange - such as, Me: "Want to take a walk?" You: "Okay." -we form a joint commitment so neither of us can simply bug out without consequences. It is a normative agreement. Subsequently, I had some interactions with Searle, who had been writing about what he called collective intentionality (25), comprising basically the institutional reality in which we all live. (He enumerates the complexities involved in ordering a cup of coffee, if one considers all the institutions behind money, commercial establishments such as coffee shops, laws governing the employment of the waiter, etc.) And it occurred to us that accounts of shared intentionality — which are fundamentally about cooperating in everything from taking a walk together to creating a social institution - might provide a powerful theoretical framework for unifying the differences we were seeing between great apes and human children across many psychological domains.

In an article for Mind and Language, Hannes Rakoczy and I (26) made a first attempt at this, but then Malinda Carpenter and I (and three other colleagues) did a much more systematic job in our 2005 article in Behavioral and Brain Sciences entitled "Understanding and Sharing Intentions" (27). In two recent books, I have provided speculative accounts on how humans' unique skills and motivations of shared intentionality arose in evolution from great apes' individual intentionality, and transformed both human cognition as well as human sociality and morality $(28,29)$. The short story is that these novel cognitive and sociomoral mechanisms occurred as the human species adapted to ever more cooperative ways of life: initially, collaborating face-to-face with a partner to forage for food (and divide the spoils equitably), and then later living cooperatively in larger cultural groups with a division of labor in which everyone had to pull his or her own weight for the group to survive and thrive (given competition with outgroups). Doing all this required individuals to take others' perspective and make recursive inferences about their mental states.

\section{METHODOLOGICAL CHALLENGES}

At various steps along the way, our comparative experimentsand our interpretation of them-have been criticized. On the one hand, ape "scoffers" such as Povinelli and Vonk (30) and Heyes (31) have criticized the research as attributing too sophisticated skills to great apes. In particular, they claim that the mindreading experiments show something like behavior reading or submentalizing rather than complex social-cognitive skills. On the other hand, ape "boosters" such as deWaal and colleagues (32) and Boesch (33) have criticized the research as attributing too little sophistication to the cognitive and social skills of great apes. In particular, they claim that the experiments on social learning and cooperation are not well suited to great apes' natural capacities in one way or another, and therefore underestimate their skills. As we have said humorously, but with a grain of seriousness, if we are being criticized equally from both directions, then we must be right (34).

A main methodological criticism is that the experimental situations are not identical for children and apes, which is of course true. But critics have often overlooked the power of control conditions. For example, both deWaal and colleagues (32) and Boesch (33) point out that in many studies, the apes, unlike the humans, are tested by a member of a different species. But the same apes that, for example, fail to understand false beliefs in some paradigm, do well in a test of knowledge/ignorance with the same experimenter in the same experimental paradigm (35).

In terms of external validity, Boesch (33) has claimed that captive apes are growing up in impoverished conditions, and so they may not develop the same skills as apes growing up in their natural environment. But Kummer (36) argues that captivity often places animals in especially challenging situations that they would never encounter in the wild, to which they must respond with cognitive skills never seen in the wild. Well-known cases are using tools, which gorillas and bonobos in captivity do systematically but gorillas and bonobos in the wild do not (37), 
and pointing for others gesturally, which apes in captivity do (for humans) but apes in the wild do not (38). While it is natural for a field worker to claim that animals in their natural environment have more skills than those in captive environments, it is not at all clear that this is the case.

A not-unrelated issue of external validity is that the children in our studies are mostly children from western educated industrialized rich democratic (WEIRD) societies (39). But a cross-cultural study by Callaghan and colleagues (40) looked at basic socialcognitive skills in infancy and toddlerhood-imitation, pointing, joint attention, helping, and collaboration - in three very different cultural contexts (two of them non-WEIRD), and found nearly identical ages of ontogenetic emergence. Of course, as children grow older, the cultural environment becomes more important, so we should expect cultural differences, which we are now beginning to investigate (41). In all this, the cultural appropriateness of the testing situation is crucial. Our solution has been to provide children with a problem they must work on with a peer or peers - with instructions from a native adult, who then leaves the room - and let them work on it by themselves (41).

\section{IMPLICATIONS FOR DEVELOPMENTAL THEORY AND RESEARCH}

Based on all this research, we propose a tentative hypothesis about how human cognitive and social ontogeny differs from that of other apes: The main factor is maturationally guided learning and cognitive construction based on humans' evolved capacities for shared intentionality. We have proposed two steps in human evolution - collaboration and culture - and our developmental proposal is that this results in two ontogenetic steps. The first step, from 9 months to 3 years, concerns children's capacities for joint intentionality (e.g., joint attention, joint commitments in collaboration) and this already differentiates children from other apes. The second step begins around age 3 and concerns children's capacities for collective intentionality (e.g., the ability to function in a group per se and to coordinate with others based on supraindividual social structures such as conventions, norms, and institutions), and this group-minded turn propels human psychology even further in a species-unique direction. Learning and cognitive construction based on these two maturational capacities (along with some evolutionarily new skills of social self-regulation) transform great ape ontogeny into human ontogeny in diverse psychological domains such as social cognition, communication, cultural learning, collaboration, prosociality, and social norms (42).

Unfortunately, few great apes are available for behavioral testing, so this research moves more slowly than others. All we can claim to have done so far is to establish some comparative facts —organized by some theoretical speculations - that hopefully get us started in the right direction toward an evolutionarily informed account of the ontogeny of uniquely human psychology.

\section{REFERENCES}

1. Bruner, J. (1975). The ontogenesis of speech acts. Journal of Child Language, 2, 1-20. https://doi.org/10.1017/S0305000900000866

2. Bates, E. (1979). The emergence of symbols: Cognition and communication in infancy. New York, NY: Academic Press.

3. Tomasello, M., \& Call, J. (in press). 30 years of great ape gestures. Animal Cognition. Advance online publication. (Special Issue)

4. Tomasello, M. (2008). Origins of human communication. Cambridge, MA: MIT Press.

5. Goodall, J. (1986). The chimpanzees of Gombe. Patterns of behavior. Cambridge, MA: Harvard University Press.

6. Nagell, K., Olguin, K., \& Tomasello, M. (1993). Processes of social learning in the tool use of chimpanzees and human children. Journal of Comparative Psychology, 107, 174-186. https://doi.org/10. 1037/0735-7036.107.2.174

7. Whiten, A. (2017). Culture extends the scope of evolutionary biology in the great apes. Proceedings of the National Academy of Sciences of the United States of America, 114, 7790-7797. https://doi.org/10. 1073/pnas.1620733114

8. Tennie, C., Call, J., \& Tomasello, M. (2009). Ratcheting up the ratchet: On the evolution of cumulative culture. Philosophical Transactions of the Royal Society, 364, 2405-2415. https://doi.org/10. 1098/rstb.2009.0052

9. Tomasello, M., Kruger, A., \& Ratner, H. (1993). Cultural learning. Behavioral and Brain Sciences, 16, 495-552. https://doi.org/10. 1017/S0140525X0003123X

10. Tomasello, M. (1999). The cultural origins of human cognition. Cambridge, MA: Harvard University Press.

11. Tomasello, M. (2016). The ontogeny of cultural learning. Current Opinion in Psychology, 8, 1-4. https://doi.org/10.1016/j.copsyc. 2015.09.008

12. Tomasello, M. (2016). Cultural learning redux. Child Development, 87, 43-53. https://doi.org/10.1111/cdev.12499

13. Premack, D., \& Woodruff, G. (1978). Does the chimpanzee have a theory of mind? Behavioral and Brain Sciences, 4, 515-526. https://doi.org/10.1017/S0140525X00076512

14. Tomasello, M., \& Call, J. (1997). Primate cognition. New York, NY: Oxford University Press.

15. Hare, B., Call, J., Agnetta, B., \& Tomasello, M. (2000). Chimpanzees know what conspecifics do and do not see. Animal Behaviour, 59, 771-785. https://doi.org/10.1006/anbe.1999.1377

16. Hare, B., Call, J., \& Tomasello, M. (2001). Do chimpanzees know what conspecifics know? Animal Behaviour, 61, 139-151. https:// doi.org/10.1006/anbe.2000.1518

17. Hare, B., Call, J., \& Tomasello, M. (2006). Chimpanzees deceive a human competitor by hiding. Cognition, 101, 495-514. https://doi. org/10.1016/j.cognition.2005.01.011

18. Call, J., \& Tomasello, M. (2008). Does the chimpanzee have a theory of mind? 30 years later. Trends in Cognitive Sciences, 12, 187192. https://doi.org/10.1016/j.tics.2008.02.010

19. Krupenye, C., Kano, F., Call, J., Hirata, S., \& Tomasello, M. (2016). Great apes anticipate that other individuals will act according to false beliefs. Science, 354, 110-114. https://doi.org/10.1126/scie nce.aaf8110

20. Buttelmann, D., Buttelmann, F., Carpenter, M., Call, J., \& Tomasello, M. (2017). Great apes distinguish true from false beliefs in an interactive helping task. PLoS ONE, 12, e0173793. https://doi.org/ 10.1371/journal.pone.0173793 
21. Melis, A., Hare, B., \& Tomasello, M. (2006). Chimpanzees recruit the best collaborators. Science, 31, 1297-1300. https://doi.org/10. 1126/science.1123007

22. Brownell, C. A., \& Carriger, M. S. (1990). Changes in cooperation and self-other differentiation during the second year. Child Development, 61, 1164-1174. https://doi.org/10.2307/1130884

23. Warneken, F., Chen, F., \& Tomasello, M. (2006). Cooperative activities in young children and chimpanzees. Child Development, 77, 640-663. https://doi.org/10.1111/j.1467-8624.2006.00895.x

24. Gilbert, M. (1990). Walking together: A paradigmatic social phenomenon. Midwest Studies in Philosophy, 15, 1-14. https://doi.org/ 10.1111/j.1475-4975.1990.tb00202.x

25. Searle, J. (1995). The construction of social reality. New York, NY: The Free Press.

26. Tomasello, M., \& Rakoczy, H. (2003). What makes human cognition unique? From individual to shared to collective intentionality. Mind \& Language, 18, 121-147. https://doi.org/10.1111/1468-0017.00217

27. Tomasello, M., Carpenter, M., Call, J., Behne, T., \& Moll, H. (2005). Understanding and sharing intentions: The origins of cultural cognition. Behavioral and Brain Sciences, 28, 675-691. https://doi.org/10.1017/S0140525X05000129

28. Tomasello, M. (2014). A natural history of human thinking. Cambridge, MA: Harvard University Press.

29. Tomasello, M. (2016). A natural history of human morality. Cambridge, MA: Harvard University Press.

30. Povinelli, D. J., \& Vonk, J. (2004). We don’t need a microscope to explore the chimpanzee's mind. Mind \& Language, 19, 1-28. https://doi.org/10.1111/j.1468-0017.2004.00244.x

31. Heyes, C. M. (2015). Animal mindreading: What's the problem? Psychonomic Bulletin \& Review, 22, 313-327. https://doi.org/10. 3758/s13423-014-0704-4

32. De Waal, F. B., Boesch, C., Horner, V., \& Whiten, A. (2008). Comparing social skills of children and apes. Science, 319, 569. https:// doi.org/10.1126/science.319.5863.569c
33. Boesch, C. (2007). What makes us human (Homo sapiens)? The challenge of cognitive cross-species comparison. Journal of Comparative Psychology, 121, 227-240. https://doi.org/10.1037/0735-7036. 121.3.227

34. Tomasello, M., \& Call, J. (2008). Assessing the validity of apehuman comparisons: A reply to Boesch (2007). Journal of Comparative Psychology, 122, 449-452. https://doi.org/10.1037/0735-7036. 122.4.449

35. Kaminski, J., Call, J., \& Tomasello, M. (2008). Chimpanzees know what others know, but not what they believe. Cognition, 109, 224234. https://doi.org/10.1016/j.cognition.2008.08.010

36. Kummer, H. (1995). In quest of the sacred baboon. Princeton, NJ: Princeton University Press.

37. McGrew, W. C. (1989). Why is ape tool-use so confusing? In V. Standen \& R. A. Foley (Eds.), Comparative socioecology. The behavioural ecology of humans and other mammals (pp. 457-472). Oxford, UK: Blackwell.

38. Tomasello, M. (2006). Why don’t apes point? In N. J. Enfield \& S. C. Levinson (Eds.), Roots of human sociality: Culture, cognition and interaction (pp. 506-530). Oxford, UK: Berg.

39. Bard, K. A., \& Leavens, D. A. (2014). The importance of development for comparative primatology. Annual Review of Anthropology, 43, 183-200. https://doi.org/10.1146/annurev-anthro-102313030223

40. Callaghan, T. C., Moll, H., Rakoczy, H., Warneken, F., Liszkowski, U., Behne, T., \& Tomasello, M. (2011). Early social cognition in three cultural contexts. Monographs of the Society for Research in Child Development, 76(Serial No. 299), 1-142. Retrieved from http://www.jstor.org/stable/41261530

41. Schäfer, M., Haun, D. B. M., \& Tomasello, M. (2015). Fair is not fair everywhere. Psychological Science, 26, 1252-1260. https://doi. org/10.1177/0956797615586188

42. Tomasello, M. (2018). Becoming human: A theory of ontogeny. Cambridge, MA: Harvard University Press. 